\title{
Progressive Collapse Analysis of RC Beams
}

\author{
G.Sukanya ${ }^{1}$, Dr.C.Natarajan ${ }^{2}$, Dr.A.Rajaraman ${ }^{3}$ \\ ${ }^{I}$ (Civil Engineering, National Institute of Technology, Tiruchirappalli, India) \\ ${ }^{2}$ (Civil Engineering, National Institute of Technology, Tiruchirappalli, India) \\ ${ }^{3}$ (Civil Engineering, Indian Institute of Technology, Madras, India)
}

\begin{abstract}
This paper investigates the nonlinear static analysis for studying the behavior of Progressive failure of RC beams. Nonlinear static analysis is strongly influenced by basic inputs like stress-strain relationship of constitutive materials, $P$ - $M$ yield interaction and moment rotation capacity of members. Normal limit state design gives only design equation for ultimate states and not its progress of collapse which gives the performance of structure like deflection and rotation. Therefore, the actual behavior of the designed singly reinforced and doubly reinforced section as it progresses to collapse is explained. For a detailed investigation, the progressive failure of $R C$ beam section with a) the influence of compressive strength of concrete, $b$ ) the influence of amount of reinforcements in a section, $c$ ) role of rotation flexibility, d) ductility and energy which is needed for seismic study and e) system behavior of simply supported beam is done.
\end{abstract}

Keywords - Decay, Ductility, Energy, Flexibility, Moment, Rotation.

\section{INTRODUCTION}

The interest on research work on the progressive collapse in civil engineering started in the early 1968 after the partial collapse of Ronan Point Apartment building in London, UK. Research efforts led to many provisions in UK standards. Later, the disproportionate collapse of the Alfred P.Murrah Federal Building (Oklahoma City, 1995) and the total collapse of the World Trade Center towers (2001), which were caused by terrorist attacks gained the interest of engineering community in the advanced research.

The term 'progressive collapse' can be defined as the collapse of all or a large part of a structure induced by failure or damage of a relatively small part of it. The structure is then forced to seek alternate load paths to redistribute the out-of-balance loads from damaged members. The redistribution of loads is a dynamic process and will continue until a new equilibrium position is reached by the structure, either by finding a stable alternate load path or by further shedding of loads as a consequence of collapsed members. For this reason, beams, columns and frame connections must be analyzed and designed in a way to handle the potential redistribution of large loads. Progressive collapse can be triggered by man-made, natural, intentional, or unintentional damage and by different actions like explosions caused by gas or explosives, earthquake, impacts of vehicles, ships or planes, human errors in the design or construction phase etc. Analyzing a structure and checking whether a progressive collapse could happen or not depends on many assumptions. These kinds of difficulties make it clear how effectively a structure should be analyzed and designed for progressive failure. Progressive collapse analysis is performed to evaluate the likelihood how the initiating damage would propagate throughout the structure causing major structural failure and the subsequent loss of life. Analysis methods used to evaluate the possibility of progressive collapse vary widely, ranging from the simple two-dimensional linear elastic static procedure to complex three-dimensional nonlinear time history analysis.

Linear static, nonlinear static, linear dynamic and nonlinear dynamic methods are four basic approaches for the progressive collapse analysis. Advantages and disadvantages of these analysis approaches have been discussed by Marjanishvili and Agnew [1]. True response of the structure can be depicted only by nonlinear analysis. Nonlinear analysis methods like nonlinear static push-over can be used for progressive collapse analysis which is commonly accepted and recommended as a reliable tool by international codes for seismic assessment of buildings. This method can be used to determine the ductility measure of the structure for lateral loading. Ductility is measured as a ratio of ultimate displacement to yield displacement. The building with large ductility results in better performance under earthquake loading.

Accuracy of the estimate of collapse and seismic capacity strongly depends on input parameters of such analysis. The basic input parameter namely moment-rotation, moment-curvature characteristics accounting for appropriate nonlinearity of constitutive materials of reinforced concrete elements is very important. Nanci Buscemi and Shalva Marjanishvili [2] presented a paper on SDOF Model for Progressive Collapse Analysis in which three different dynamic techniques were discussed considering single degree of freedom model. The importance of stiffness and initial conditions for progressive failure was described [2]. The effects of plastic hinge properties in nonlinear analysis of reinforced concrete buildings was conferred by Mehmet Inel and Hayri Baytan Ozmen[3] which signifies the importance of modeling of hinges of building and point outs that hinges 
depends upon the type of element, material properties, longitudinal and transverse steel content, and the axial load level on the element. Ali Kheyroddin and Hosein Naderpour presented a paper on plastic hinge rotation capacity of reinforced concrete beams. The plastic hinge rotation capacity and the effect of the loading type on the beam were the two important criteria considered [4]. The influence of the tension reinforcement and the bending moment distribution (loading type) on the ultimate deformation characteristics of reinforced concrete (RC) beams for 15 simply supported beams with different amounts of tension reinforcement ratio under three different loading conditions were compared [4]. Moment curvature of reinforced concrete beams using various confinement models and experimental validation by M. Srikanth, G. Rajesh Kumar and S. Giri [5] signifies the effects of confinements in the moment curvature behavior.

Thus progressive collapse analysis is strongly influenced by basic inputs like stress-strain relationship of constitutive materials, P-M yield interaction and moment rotation capacity of members. So this paper aims to study the actual behavior of the reinforced concrete beam section with a) the influence of compressive strength of concrete and b) the influence of reinforcement on the section on account of progressive failure.

\section{Moment Rotation Relationship}

Moment-rotation relationships of RC beams provide an estimate of ductility of beams, which is a valuable design parameter. The correct estimate of ductility is very important in the context of recent advancements in design approaches like displacement-based design. The nonlinearity of concrete is given by the relationship between stress and strain distribution in concrete which is given as parabola in the code IS 456:2000.

Normal limit state design, IS 456:2000 gives only design equation for ultimate state and not its progress which will give performance like deflection, curvature and rotation. The difference between the design and actual behavior of the section with the experimental test data from the reference paper for $f c k=20$ is well depicted in fig 1. Moment and its corresponding rotation for frame elements can be calculated from its stress strain curve of concrete. To understand this, a rectangular section is taken and its moment and corresponding rotations for different strains varying from 0.001 to 0.0035 considering elastic, elasto-plastic and perfectly plastic stages is studied and presented in this paper.

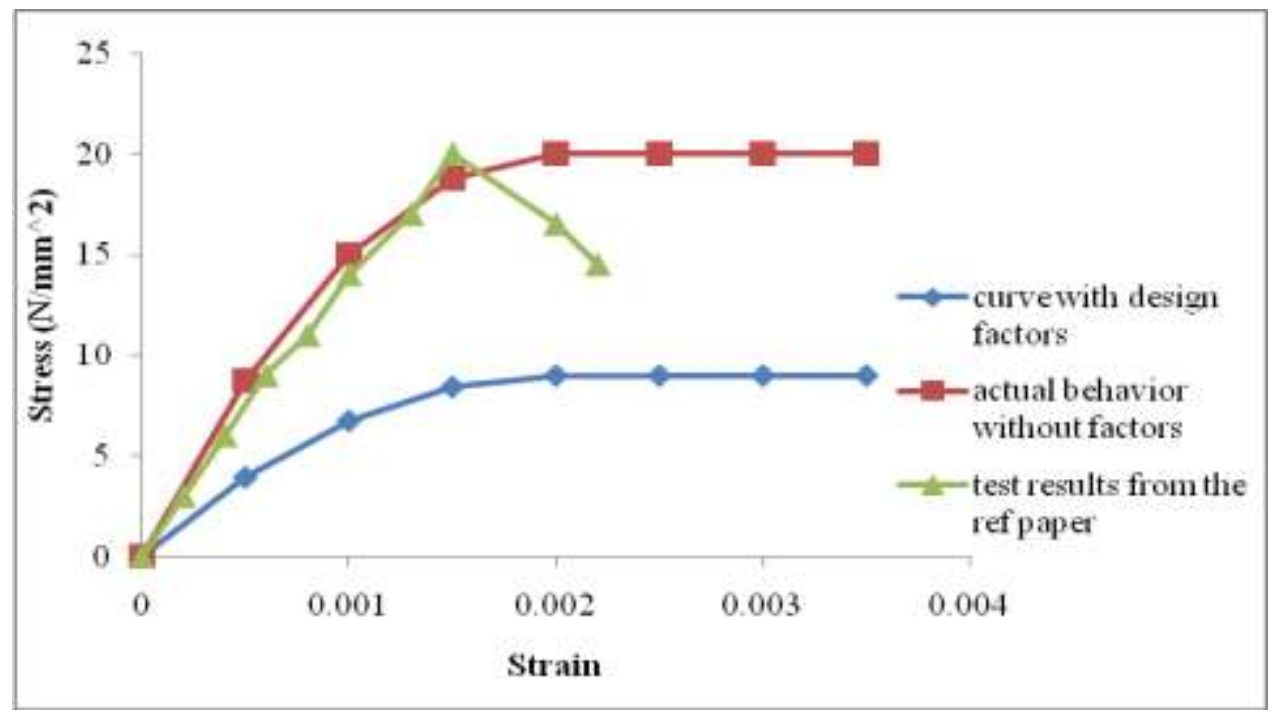

Fig 1 Stress Strain curve for concrete

\subsection{Moment and Rotation Calculation}

The maximum strain in concrete at the outermost compression fiber is taken as 0.0035 in bending as per IS 456:2000. Therefore to realize the actual behavior, the strain is divided into ' $n$ ' increments and the following procedure is considered for finding the actual moment rotation behavior of the section.

- Initially a general parabolic equation is formed considering the fig 1 for the curve without design factors as Stress $=(1000 * f c k *$ strain $)-\left(250000 * f c k *\right.$ strai $\left.^{2}\right)$

- Using this equation, stresses corresponding to the strains are calculated.

- From this stress and strain, actual modulus of elasticity is found.

- For increments of strains, corresponding to the strain diagram, the neutral axis depth $(\mathrm{Xu})$ are calculated and at each step it is checked for yield stress and maximum(ultimate) strain of tension reinforcement. From neutral axis, lever arm is calculated. 
- Moment of resistance $=$ resultant compressive force * lever arm

- Rotation $=$ Extreme compressive strain $/ \mathrm{Ku}$

The following study is done by varying one material parameter (fck) and one design parameter (amount of reinforcement used) for understanding the moment rotation behavior since it determines the plastic hinge properties. So the study concentrates on the actual behavior of designed section as it progresses to collapse stage, the design factors according to IS 456:2000 are not taken into account in this paper.

And for each of the study considered, the general common parameters considered are as follows,

- Characteristic cube compressive strength of concrete, $f_{c k}=20 \mathrm{~N} / \mathrm{mm}^{2}$

- Characteristic strength of steel, $\mathrm{f}_{\mathrm{y}}=415 \mathrm{~N} / \mathrm{mm}^{2}$

- $\quad$ Breadth of beam, $b=230 \mathrm{~mm}$

- Depth of the beam, $\mathrm{D}=480 \mathrm{~mm}$

- Clear cover, cc=20mm

- Diameter of bars used, dia=20mm

- $\quad$ Effective depth of beam, $\mathrm{d}=450 \mathrm{~mm}$

- Span, $1=6 \mathrm{~m}$

- Area of reinforcement in tension side, $\mathrm{A}_{\mathrm{st}}=980 \mathrm{~mm}^{2}$ ( which is under-reinforced in both actual and design case)

- $\quad$ Actual balanced $\mathrm{A}_{\mathrm{st}}=1867 \mathrm{~mm}^{2}$

- Modulus of elasticity of steel, $\mathrm{E}_{\mathrm{s}}=2 * 10^{5} \mathrm{~N} / \mathrm{mm}^{2}$

\section{Role Of Compressive Strength Of Concrete On Section Failure}

The moment rotation behavior of rectangular beam section is studied by varying the material parameter, i.e., compressive strength of concrete, fck, from 20 to 60 and keeping other parameters constant which are as mentioned above. Fig 2 depicts the nonlinear stress strain relationship for various fck and it illustrates that for higher the grade of concrete, the steeper is the initial portion of the curve and for low strength concrete, the curve is relatively flat. In order to have a clear picture, the curves are normalized with fck=20 and yield strain $=0.002$, which specifies the increase in strength for various fck with respect to fck=20. Fig 3 shows how the ratio of secant modulus of elasticity of concrete to static modulus of elasticity varies with respect to strain. The modulus of elasticity falls at higher rate till the strain 0.002 and after that the curves are almost linear. Moment and rotation of the RC beam section are calculated as per the procedure mentioned above. Fig 4 clearly illustrates moment rotation behavior of RC beam section for various fck. It is clear that increase of compressive strength of concrete increases moment of resistance but not its rotation. To realize the effects, fig 5 shows the variation of moments for various fck with respect to the strains. The higher the grade of concrete, lesser the failure strain because even though the concrete strength is high, the steel, which was kept constant throughout, yields. Fig 6 shows the normalized curves of moment and rotation behavior with respect to fck=20. To understand it much better the normalized moment and normalized rotation are plotted with respect to normalized strain in fig 7 and fig 8. Normalized rotation flexibility, the moment required to produce unit rotation is plotted with normalized strain in fig 9 and it also describes how the failure strain varies for different fck. The curves are normalized with fck $=20$ and yield strain $=0.002$. The drops in the fig 9 depicts the behavior of various fck after yielding of steel and the section becoming brittle on increasing fck.

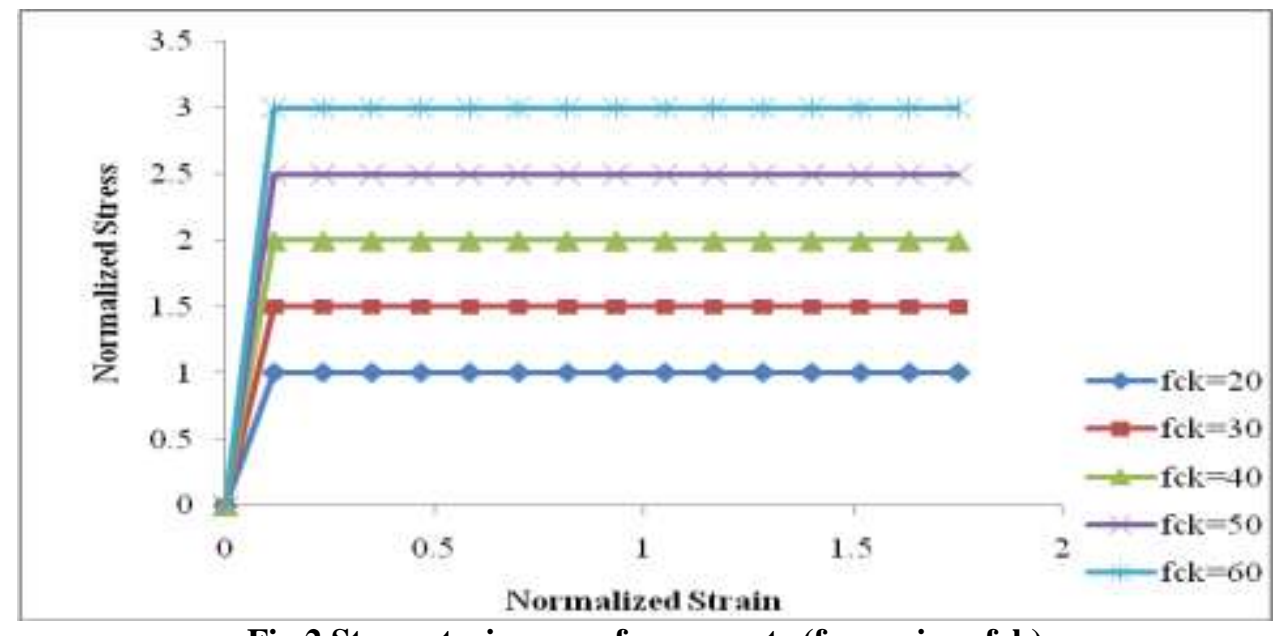

Fig 2 Stress strain curve for concrete (for various fck) 


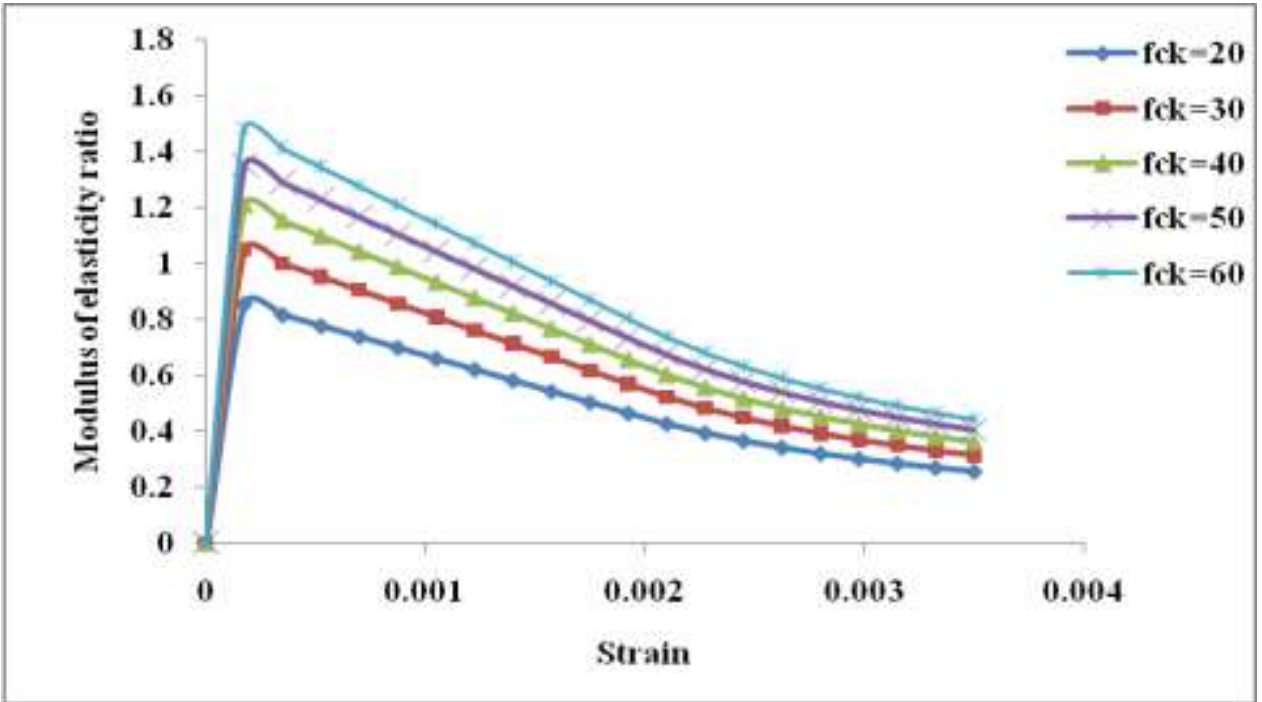

Fig 3 Modulus of Elasticity ratio vs Strain (for various fck)

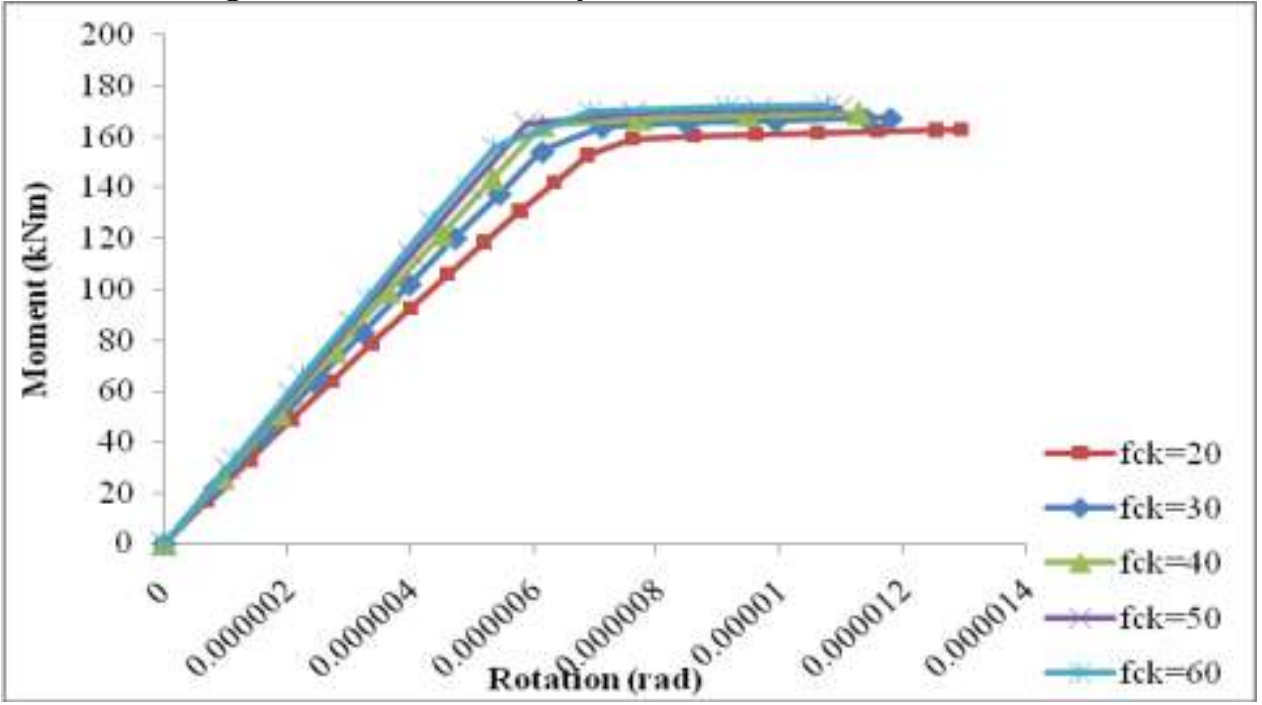

Fig 4 Moment vs Rotation (for various fck)

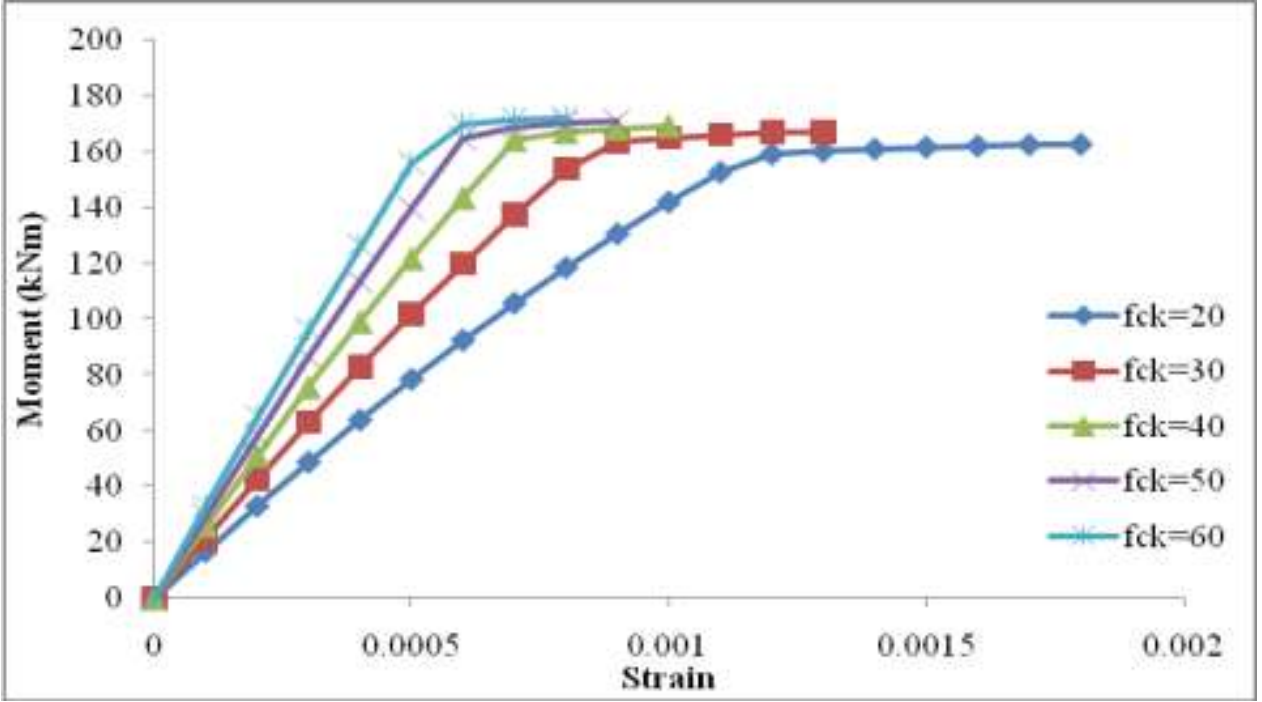

Fig 5 Moment vs Strain (for various fck) 


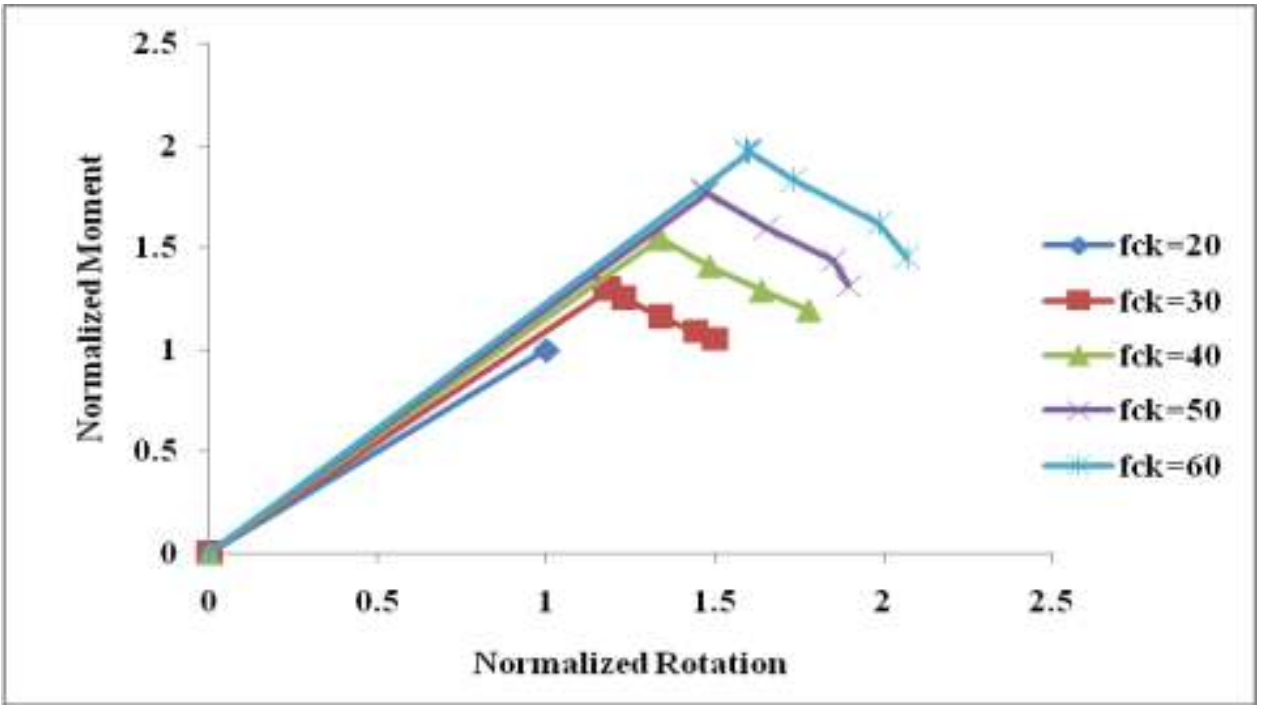

Fig 6 Normalized Moment vs Normalized Rotation (for various fck)

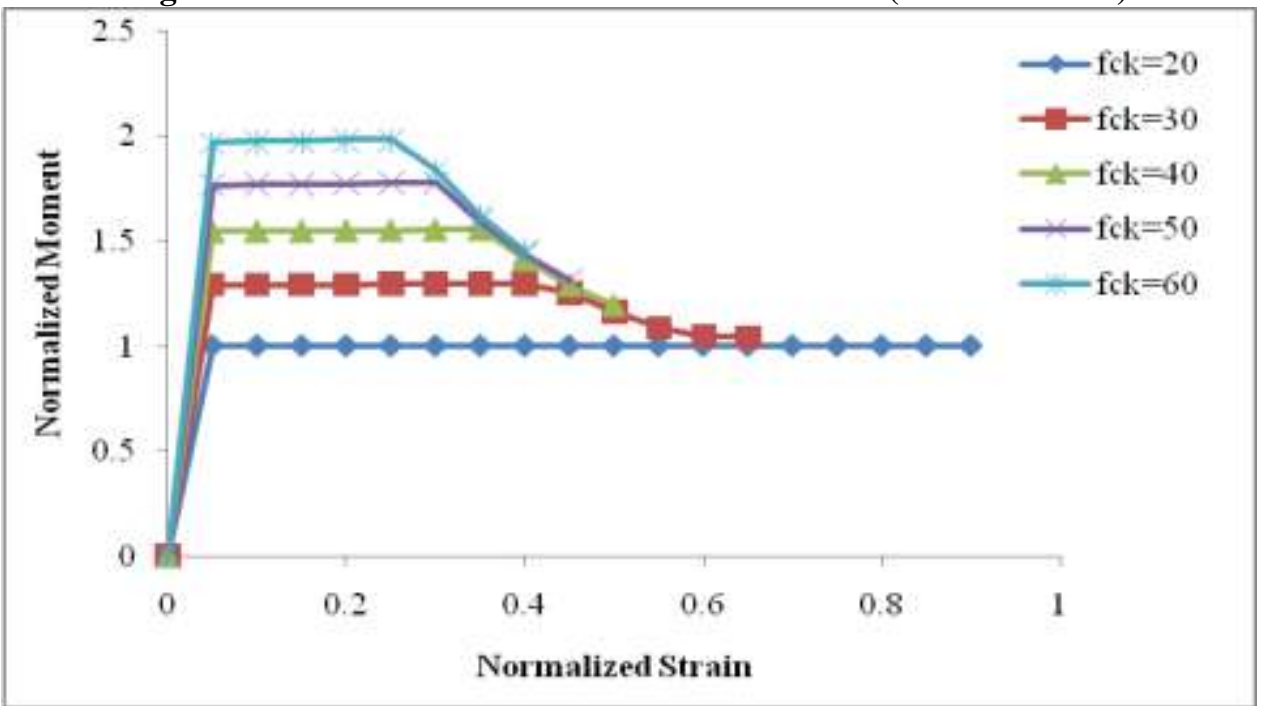

Fig 7 Normalized Moment Vs Normalized Strain (for various fck)

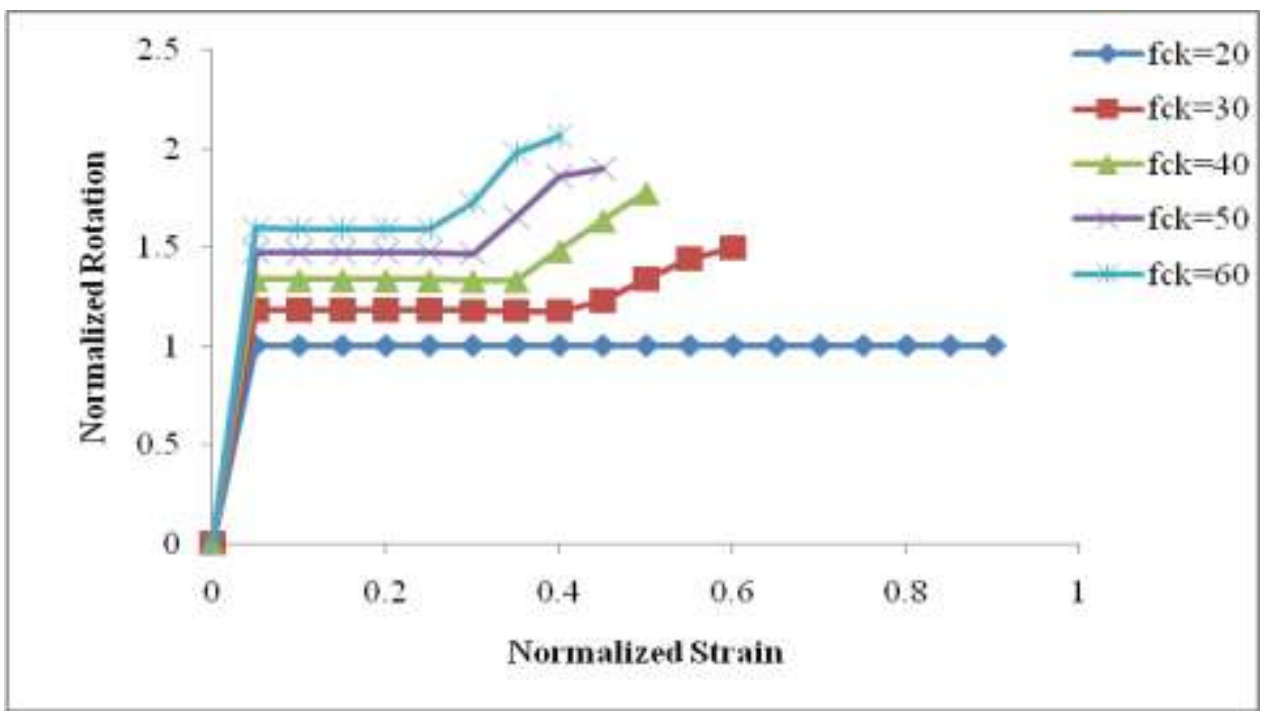

Fig 8 Normalized Rotation Vs Normalized Strain (for various fck) 


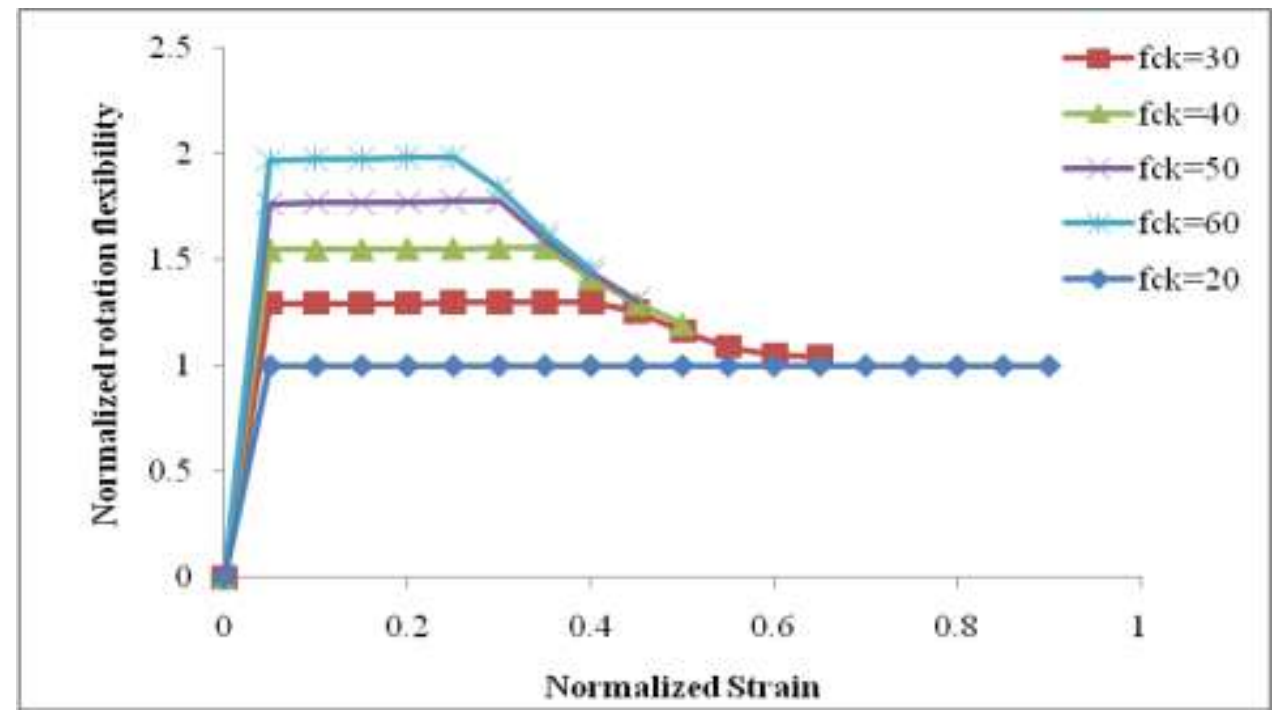

Fig 9 Normalized Rotation Flexibility vs Normalized Strain (for various fck)

Rotation ductility or rotation capacity is the one which controls the ability to redistribute the moment and fail gradually. It is the ratio of ultimate rotation to yield rotation (the point at which the steel has yielded). Energy is important for seismic performance evaluation of the building. In this study it is calculated as the area under the moment rotation curve. To value the nature of rotation ductility and energy for various fck, fig 10 is plotted which is the normalized rotation ductility and normalized energy with respect to fck $=20$. Table 1 shows the percentage reduction of rotation ductility on increasing fck. There is $8.92 \%$ reduction in rotation ductility when $\mathrm{fck}=30$ is used in the section on comparison with $\mathrm{fck}=20$ and other reduction percentages are presented in the table 1 . As fck increases the energy decreases and the $\%$ reduction in the energy for various fck when compared to fck=20 is shown in the table 2 .

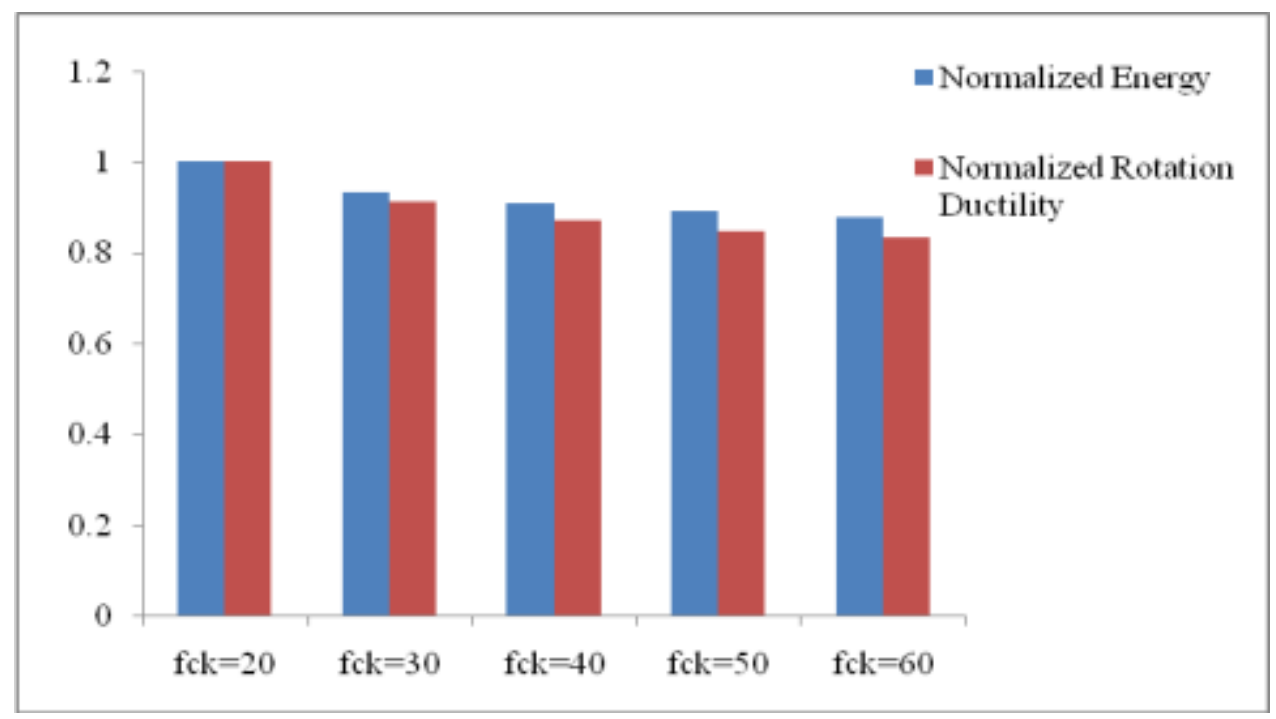

Fig 10 Energy and Rotation Ductility (for various fck)

Table 1 Percentage change of rotation ductility for various fck

\begin{tabular}{|c|c|c|}
\hline Compressive strength & Normalized Rotation Ductility & Percentage reduction in comparison to fck=20 \\
\hline fck=20 & 1 & - \\
\hline fck $=30$ & 0.91 & 8.92 \\
\hline fck $=40$ & 0.87 & 12.82 \\
\hline fck=50 & 0.85 & 15.19 \\
\hline fck $=60$ & 0.83 & 16.81 \\
\hline
\end{tabular}


Table 2 Percentage change of Energy for various fck

\begin{tabular}{|c|c|c|}
\hline Compressive strength & Energy & $\begin{array}{c}\text { Percentage reduction in } \\
\text { comparison to fck=20 }\end{array}$ \\
\hline $\mathrm{fck}=20$ & 1 & - \\
\hline $\mathrm{fck}=30$ & 0.93 & 6.87 \\
\hline $\mathrm{fck}=40$ & 0.91 & 9.30 \\
\hline $\mathrm{fck}=50$ & 0.89 & 10.84 \\
\hline $\mathrm{fck}=60$ & 0.88 & 12.09 \\
\hline
\end{tabular}

\section{Role Of Reinforcement On Section Failure}

The behavior of beam in nonlinear phase depends on amount of reinforcement in tension and compression side. Low amount of reinforcement can cause fracture of steel during dynamic loading. The following study is done by varying amount of reinforcement in tension side, from minimum Ast to Ast (which is under-reinforced in both design and actual) i.e., $0.2 *$ Ast, $0.4^{*}$ Ast, $0.6^{*}$ Ast, $0.8^{*}$ Ast \& Ast and keeping other parameters constant as mentioned above. The fig 11 shows the moment rotation behavior of singly reinforced beam cross section for various $\%$ of Ast with the actual behavior of moment rotation for balanced Ast is also shown.
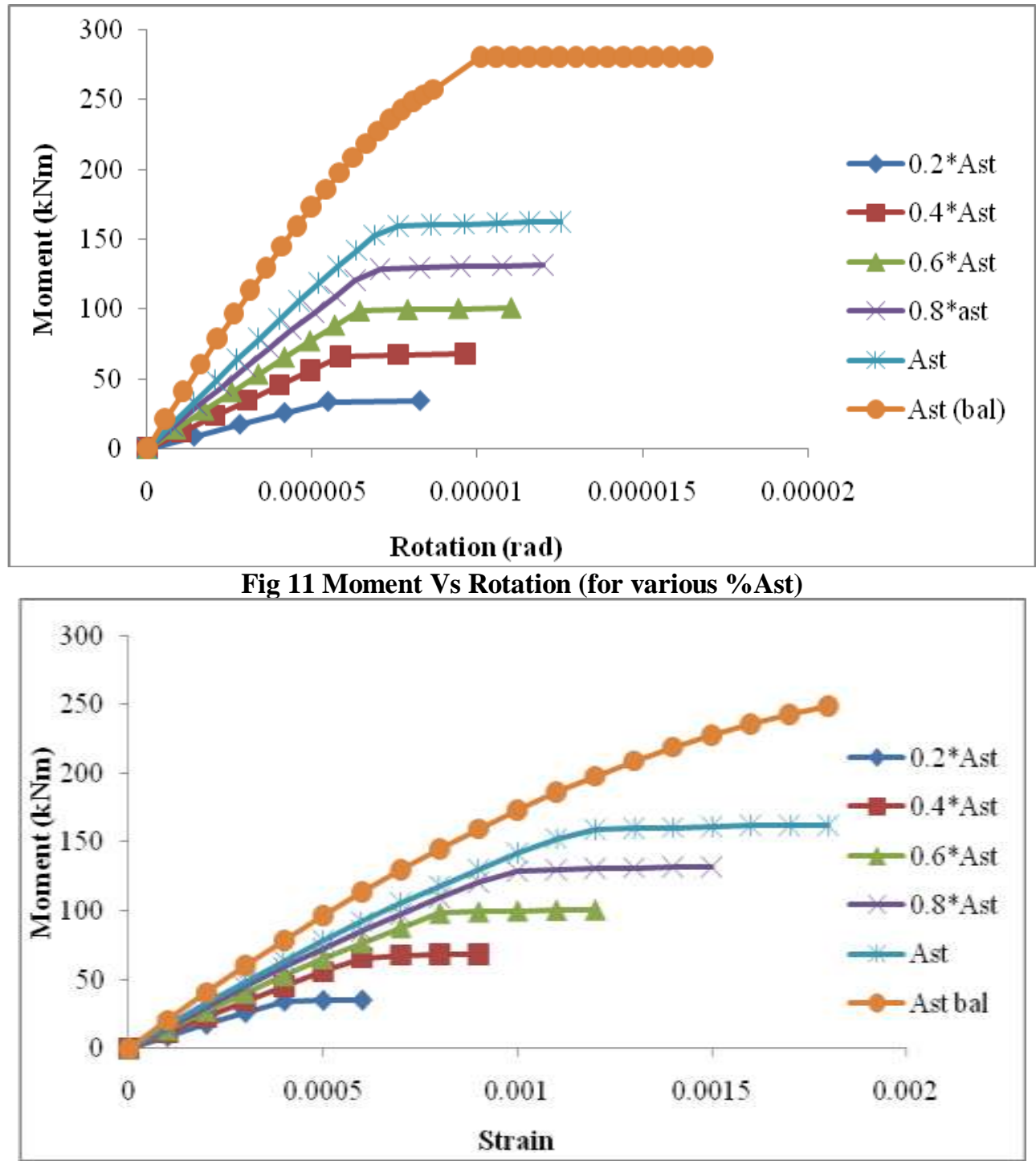

Fig 12 Moment vs Strain (for various \% Ast)

Fig 11 portrays the increase in moment and rotation on the increase of amount of steel in tension side and fig 12 clearly renders the increase in moment resistance and also the increase in the failure strain with the increase in tension reinforcement. 


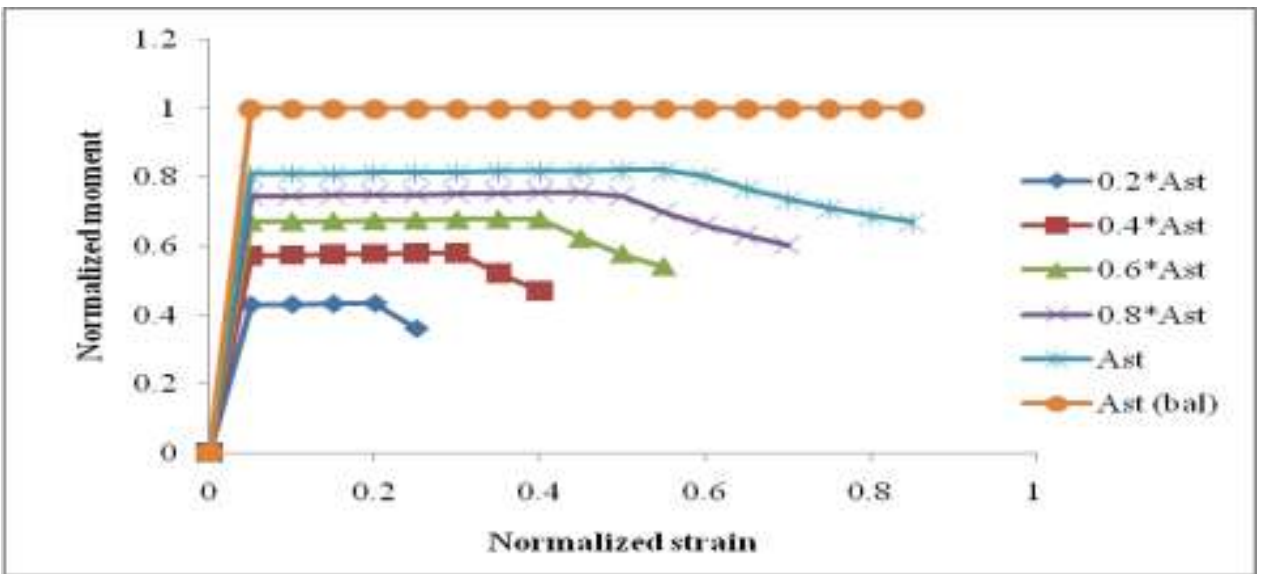

Fig 13 Normalized Moment vs Normalized Strain (for various \% Ast)

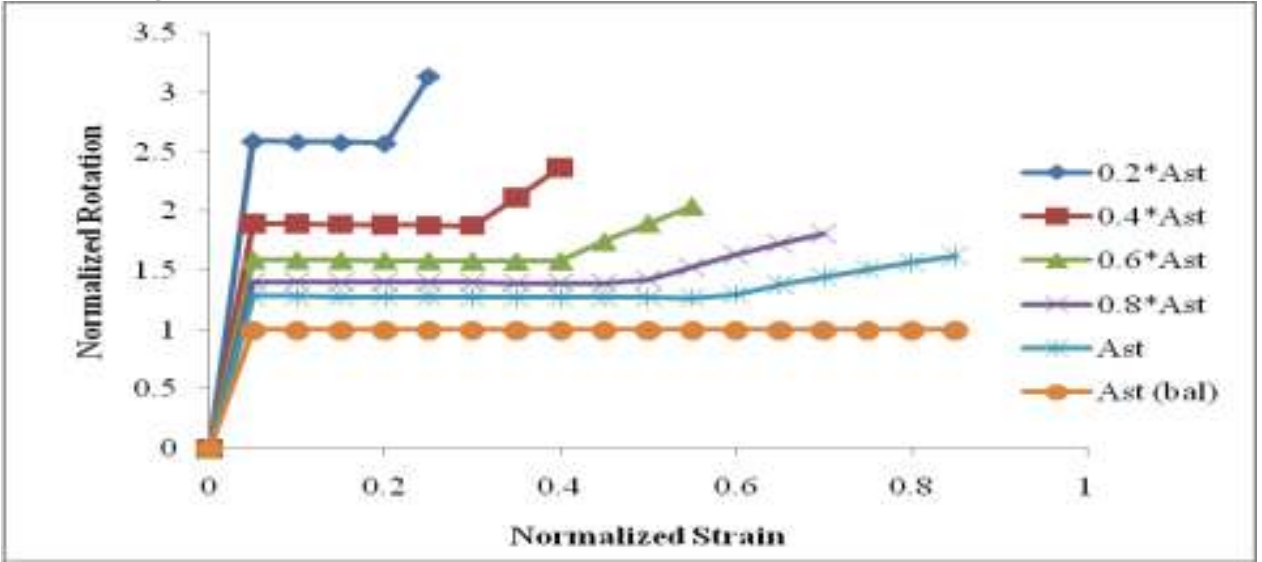

Fig 14 Normalized Rotation vs Normalized Strain (for various \% Ast)

To reveal the clear picture, the moment and rotation, are normalized with respect to the actual balanced Ast, are plotted with respect to normalized strain in fig 13 and fig 14. Fig 13 describes the fall in moment after the yielding of steel with respect to actual balanced Ast and fig 14 describes the amount of increase in rotation after the yielding of steel as \%Ast increases in tension side with respect to actual balanced Ast confirming the ductile mode of failure. Fig 14 clearly marks how the under-reinforced section gains more rotation on increasing the amount of reinforcement in tension side. Fig 15 clearly depicts the normalized rotation flexibility from which the moment rotation behavior can be understood on the increase of strain. A decrease in rotation flexibility with respect to actual balanced Ast indicates that lesser moment is required for rotation as it approaches collapse. Table 3 gives the percentage change of normalized rotation ductility with respect to actual balanced Ast. As the tension reinforcement is increased till balanced Ast, the rotation ductility increases and fig 16 portrays normalized rotation ductility and normalized energy variation for various percentage of Ast.

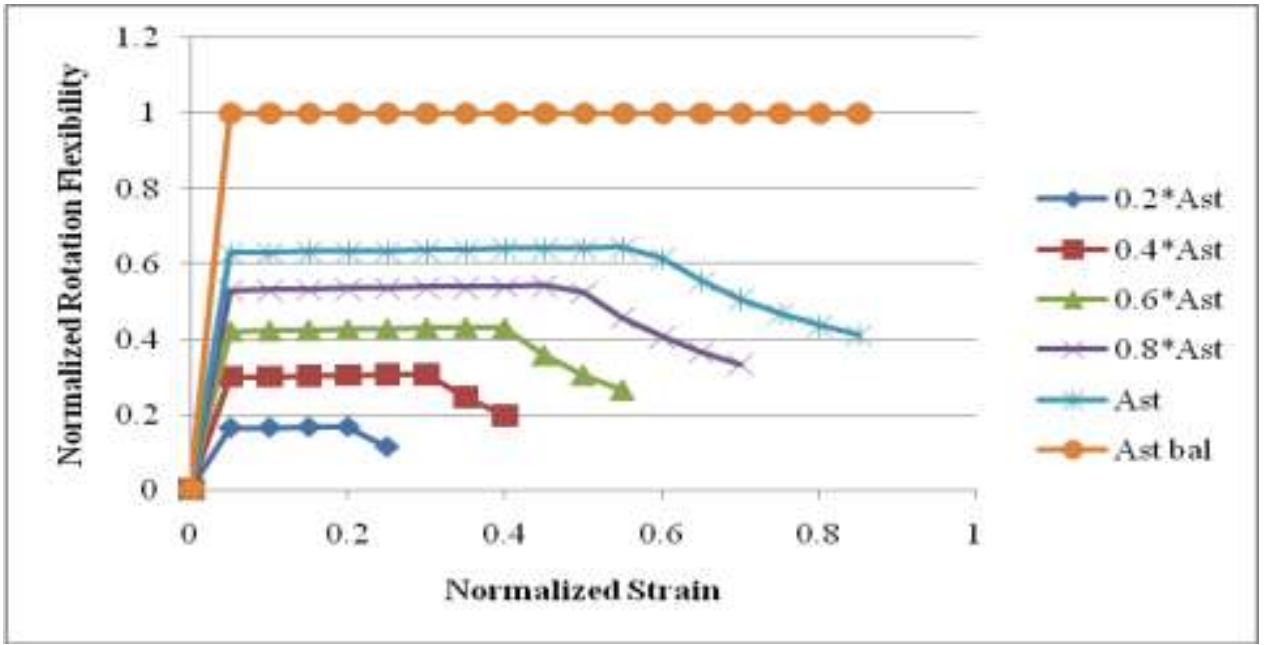

Fig 15 Normalized Rotation Flexibility vs Normalized Strain (for various \% Ast) 
Table 3 Percentage change of rotation ductility of various \% Ast

\begin{tabular}{|c|c|c|}
\hline $\begin{array}{c}\text { Amount of tension } \\
\text { reinforcement }\end{array}$ & Normalized Rotation ductility & $\begin{array}{c}\text { Percentage reduction with } \\
\text { respect to Ast ( actual balanced) }\end{array}$ \\
\hline $0.2^{*} \mathrm{Ast}$ & 0.61 & 38.77 \\
\hline $0.4^{*} \mathrm{Ast}$ & 0.65 & 34.84 \\
\hline $0.6^{*} \mathrm{Ast}$ & 0.69 & 31.23 \\
\hline $0.8^{*} \mathrm{Ast}$ & 0.72 & 27.51 \\
\hline Ast & 0.77 & 23.17 \\
\hline Ast (bal) & 1 & - \\
\hline
\end{tabular}

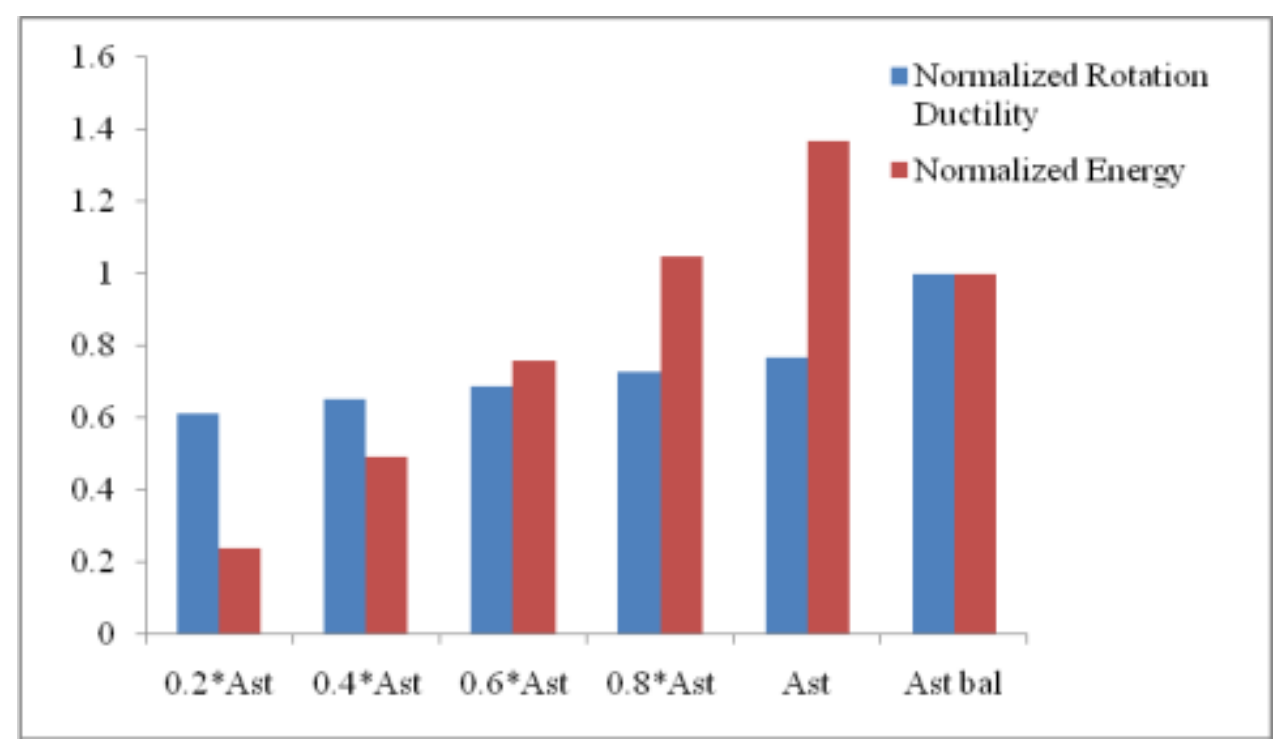

Fig 16 Energy and Rotation Ductility (for various \% Ast)

Table 4 Percentage change of Energy for various \% Ast

\begin{tabular}{|c|c|c|}
\hline Amount of tension reinforcement & Normalized Energy & Percentage change \\
\hline $0.2^{*} \mathrm{Ast}$ & 0.24 & +76.37 \\
\hline $0.4^{*} \mathrm{Ast}$ & 0.49 & +51.16 \\
\hline $0.6^{*} \mathrm{Ast}$ & 0.76 & +24.23 \\
\hline $0.8^{*} \mathrm{Ast}$ & 1.05 & -4.64 \\
\hline Ast & 1.37 & -36.96 \\
\hline Ast (bal) & 1 & - \\
\hline
\end{tabular}

Table 4 gives energy i.e., the area under the moment rotation curve for various percentage of Ast with respect to actual balanced Ast. The positive sign in the table denotes the decrease in energy and the negative sign denotes the increase in energy which was normalized with respect to the actual balanced Ast. As the percentage of steel of the RC beam section increases in tension side, the energy and rotation capacity increases.

Excess of steel in tension side doesn't increase moment carrying capacity that is why we go for doubly reinforced section. Compression steel ensures that the tension steel yields before the concrete crushes, indicating that it helps changing the failure mode to tension controlled. Thus in this study, the moment rotation behavior of rectangular beam section is studied by varying the design parameter, i.e., area of steel in compression side to understand the effect of singly reinforced section when used as doubly reinforced section, varying Asc from $\mathrm{Asc}=$ minimum $\%$ Ast to Asc=Ast and keeping other parameters constant as mentioned above. Fig 17 exposes the increase in moment resistance of the doubly reinforced section in comparison to the singly reinforced section and also the failure strain variation for the varying amount of reinforcement in the compression side. 


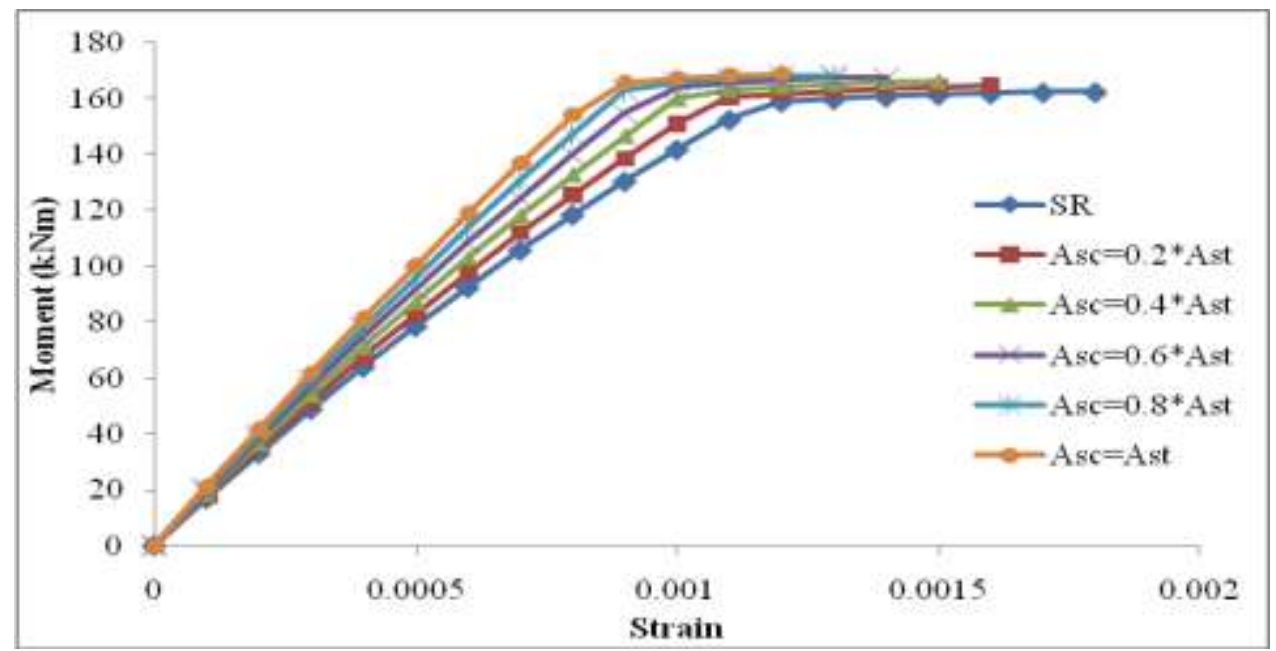

Fig 17 Moment vs Strain (for various \% Asc)

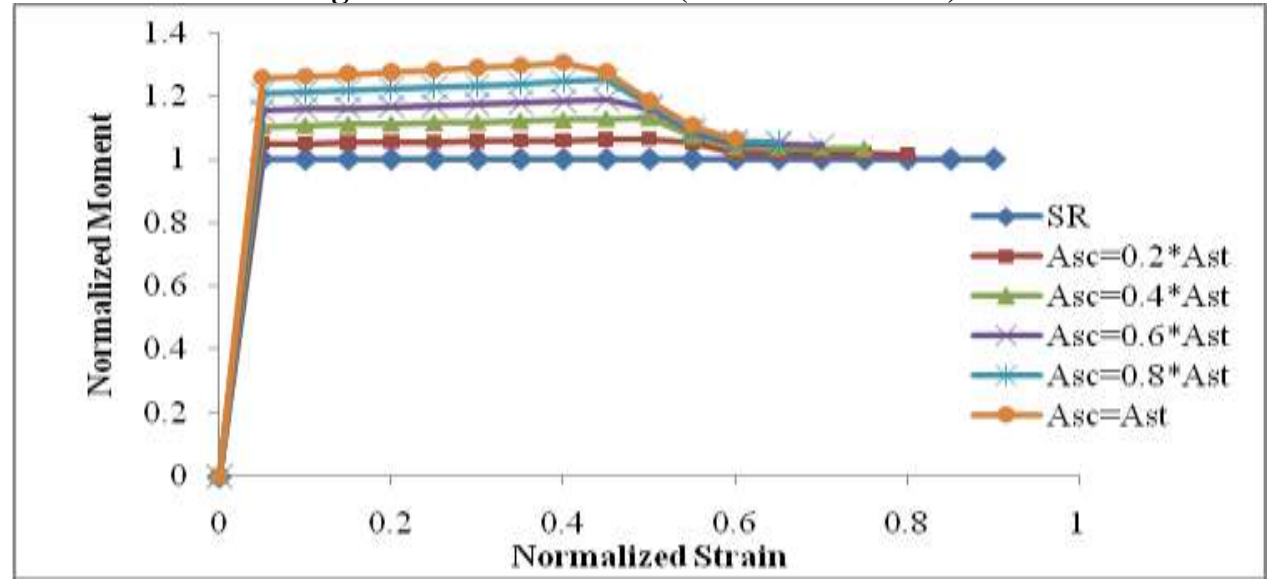

Fig 18 Normalized Moment vs Normalized Strain (for various \% Asc)

The fig 18 represents the normalized moment of doubly reinforced RC beam section vs normalized strain with respect to singly reinforced $\mathrm{RC}$ beam section moments and with yield strain $=0.002$. When the singly reinforced section is used as doubly reinforced section with Asc=Ast, there is a $30 \%$ increase in moment carrying capacity. The fall in plots of fig 18 represents the yielding of tension steel. Fig 20 shows the variation of normalized rotation flexibility with respect to normalized strain for various percentage of steel in compression side. It can be observed that there is a sudden change in rotation flexibility as the steel reaches its first yield point and rotation flexibility decreases as it approaches collapse. Moment required to cause collapse decreases on the increase of strain.

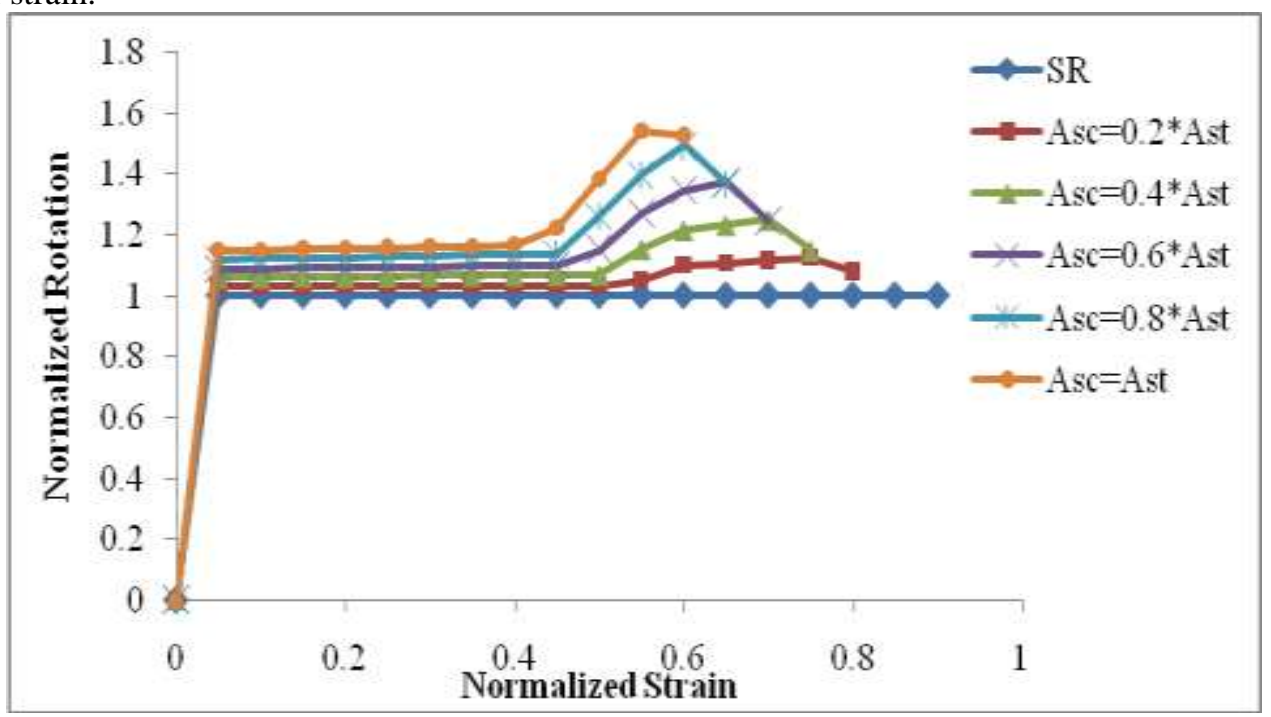

Fig 19 Normalized Rotation vs Normalized Strain (for various \% Asc) 
Table 5 shows the percentage reduction in normalized rotation ductility with respect to singly reinforced RC beam section for various percentage of $\mathrm{Asc}=\%$ Ast. Rotation ductility decreases as the amount of reinforcement in compression side increases. Fig 21 portrays the percentage reduction in rotation ductility and energy for various amount of steel in compression reinforcement. Table 6 shows the percentage reduction in normalized energy with respect to singly reinforced RC beam section for various percentage of Asc $=\%$ Ast. Area under moment rotation curve i.e., energy decreases as the amount of reinforcement in compression side increases.

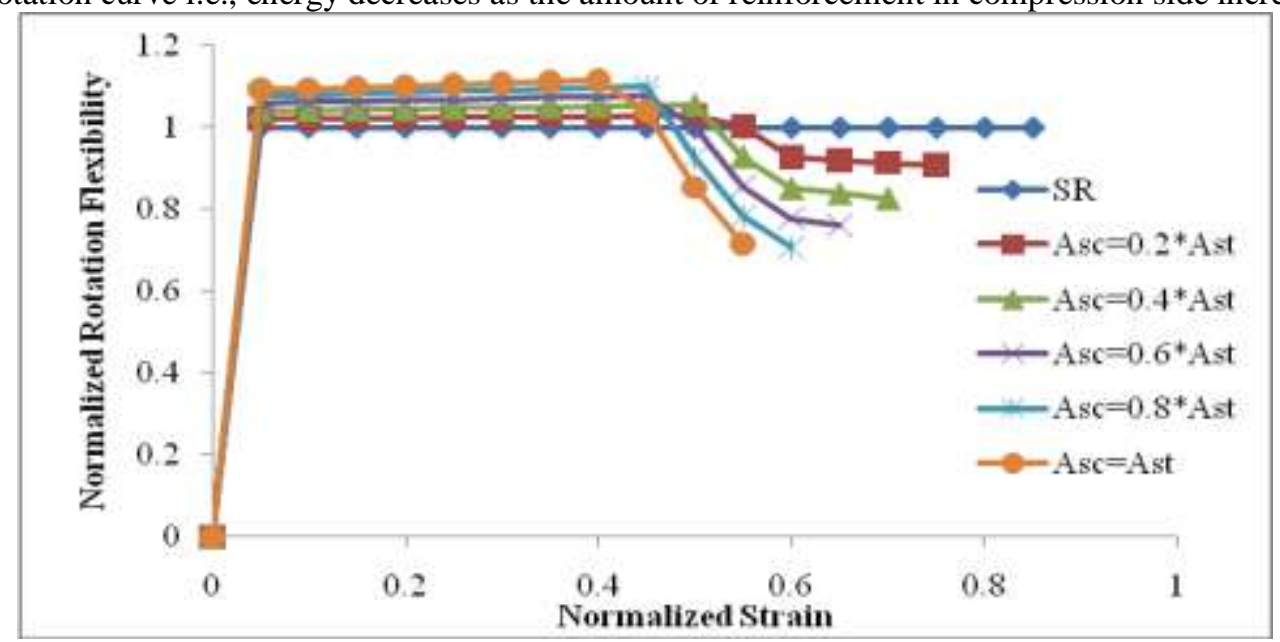

Fig 20 Normalized Rotation Flexibility vs Normalized Strain (for various \% Asc)

Table 5 Percentage change of rotation ductility for various Asc=\% Ast

\begin{tabular}{|l|c|c|}
\hline Amount of compressive reinforcement & Normalized Rotation ductility & Percentage reduction \\
\hline $\mathrm{SR}$ & 1 & - \\
\hline $\mathrm{Asc}=0.2^{*} \mathrm{Ast}$ & 0.97 & 3.36 \\
\hline $\mathrm{Asc}=0.4^{*} \mathrm{Ast}$ & 0.94 & 5.70 \\
\hline $\mathrm{Asc}=0.6^{*} \mathrm{Ast}$ & 0.92 & 7.50 \\
\hline $\mathrm{Asc}=0.8^{*} \mathrm{Ast}$ & 0.91 & 8.97 \\
\hline Asc $=$ Ast & 0.90 & 10.20 \\
\hline
\end{tabular}

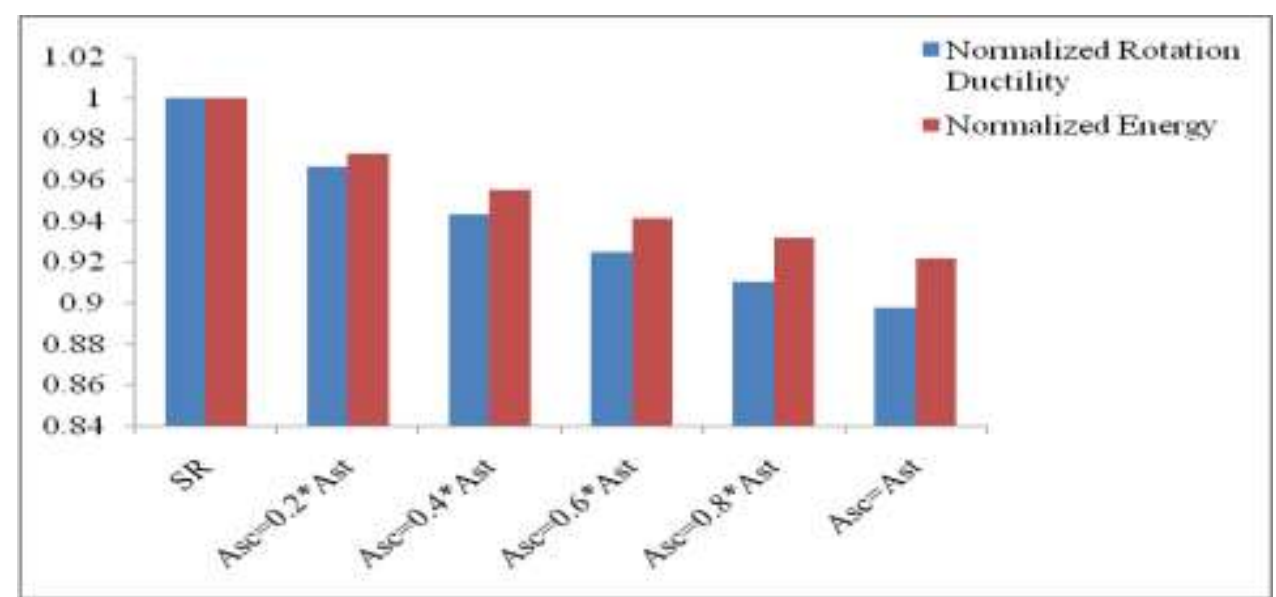

Fig 21 Energy and Rotation Ductility (for various \% Asc)

Table 6 Percentage change of Energy for various Asc=\% Ast

\begin{tabular}{|l|c|c|}
\hline Amount of compressive reinforcement & Energy & Percentage reduction \\
\hline $\mathrm{SR}$ & 1 & - \\
\hline $\mathrm{Asc}=0.2^{*}$ Ast & 0.97 & 2.73 \\
\hline $\mathrm{Asc}=0.4^{*}$ Ast & 0.96 & 4.49 \\
\hline $\mathrm{Asc}=0.6^{*}$ Ast & 0.94 & 5.87 \\
\hline Asc $=0.8^{*}$ Ast & 0.93 & 6.82 \\
\hline Asc $=$ Ast & 0.92 & 7.81 \\
\hline
\end{tabular}




\section{Role Of Section Failure On System Behaviour}

To study the role of section failure on system behaviour, a beam with simply supported ends (ie, one end is pinned and other end is roller) is considered with concentrated load at the mid-span in one case and uniformly distributed load along the span in other case. In this beam a hinge is assumed to form at the mid-span and the load $\mathrm{P}$ is divided into $\mathrm{n}$ steps and applied incrementally. In each step, the analysis is done by varying the stiffness of the hinge. For simply supported beam, singly reinforced beam section properties are taken for the calculation of stiffness. The system parameters considered are a) number of elements, ne=10, b) number of nodes of the system, $n n=n e+1$ and c) yielding length $=$ span/20. Stiffness is then calculated by dividing the load with deflection. The rotation flexibility is calculated by dividing the moment by relative rotation of the hinge. The following figures reveal the nature of stiffness and rotation flexibility of the RC beam on the increase of load and sudden fall shows exposes that the tension reinforcements are yielded.

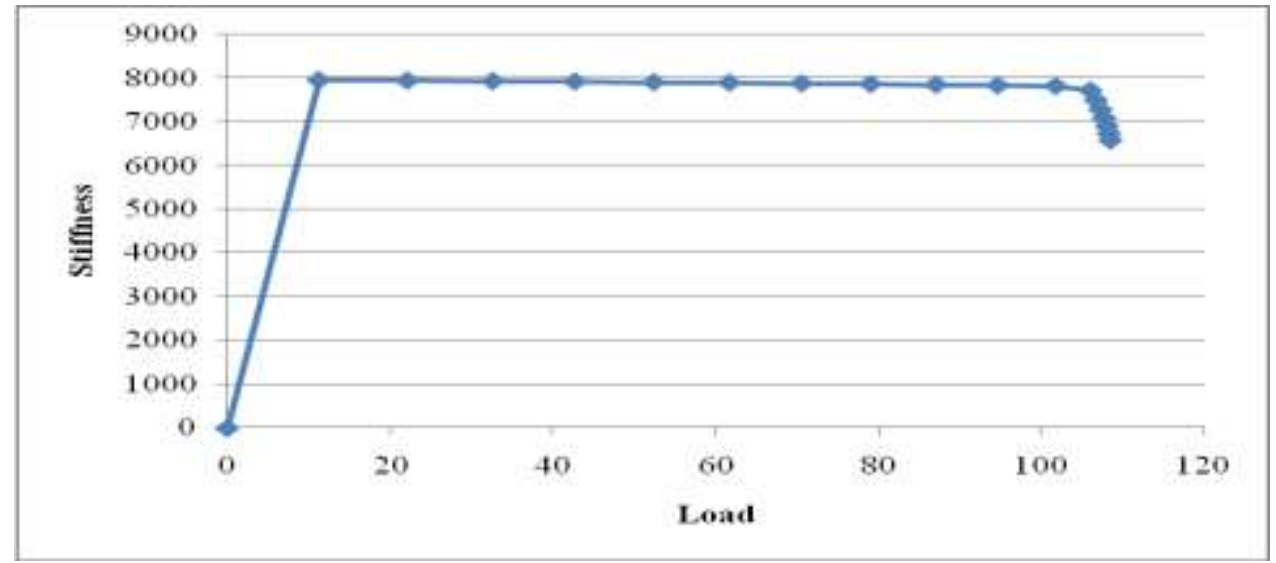

Fig 22 Stiffness vs Load (for concentrated load at mid-span)

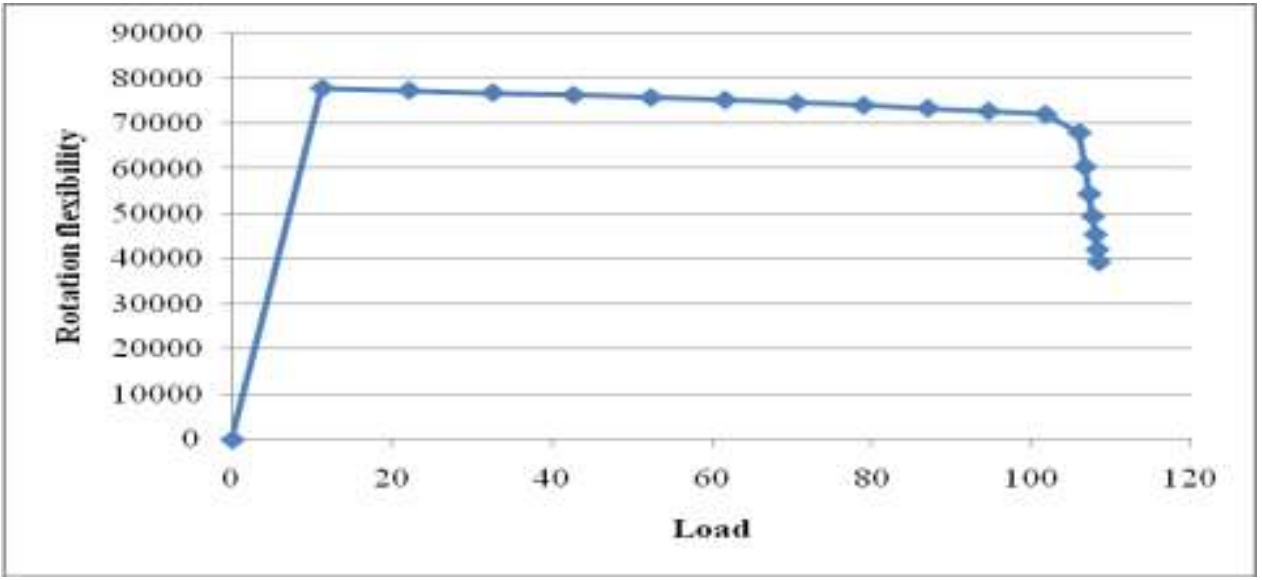

Fig 23 Rotation Flexibility vs Load (for concentrated load at mid-span)

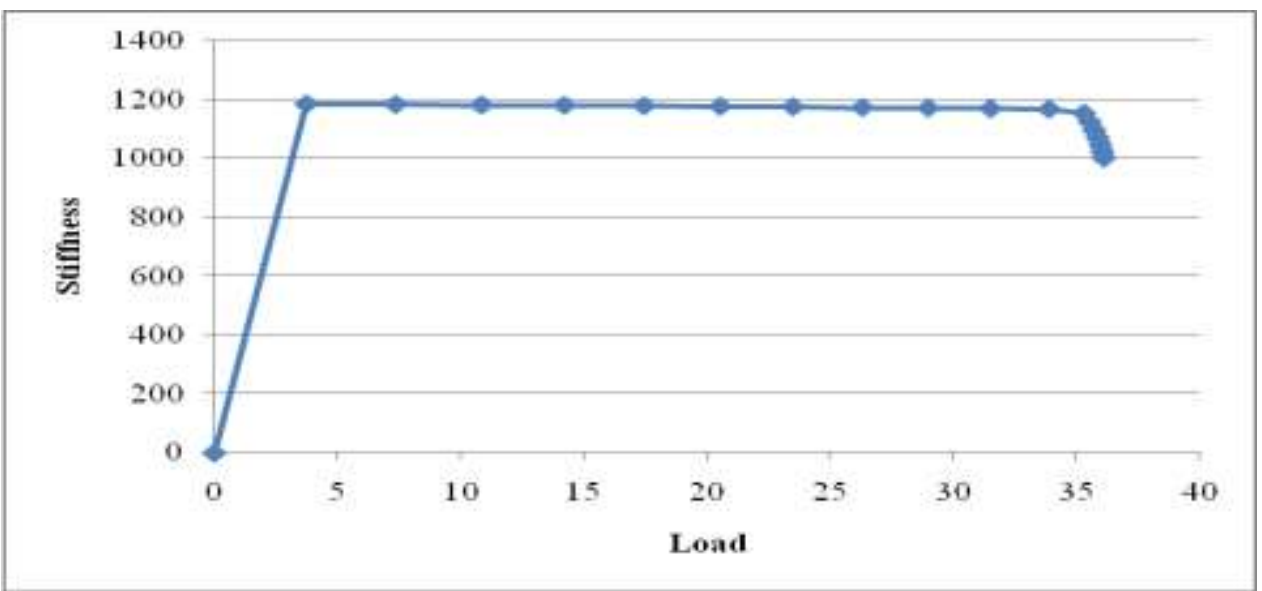

Fig 24 Stiffness vs Load (for uniformly distributed load along the span) 


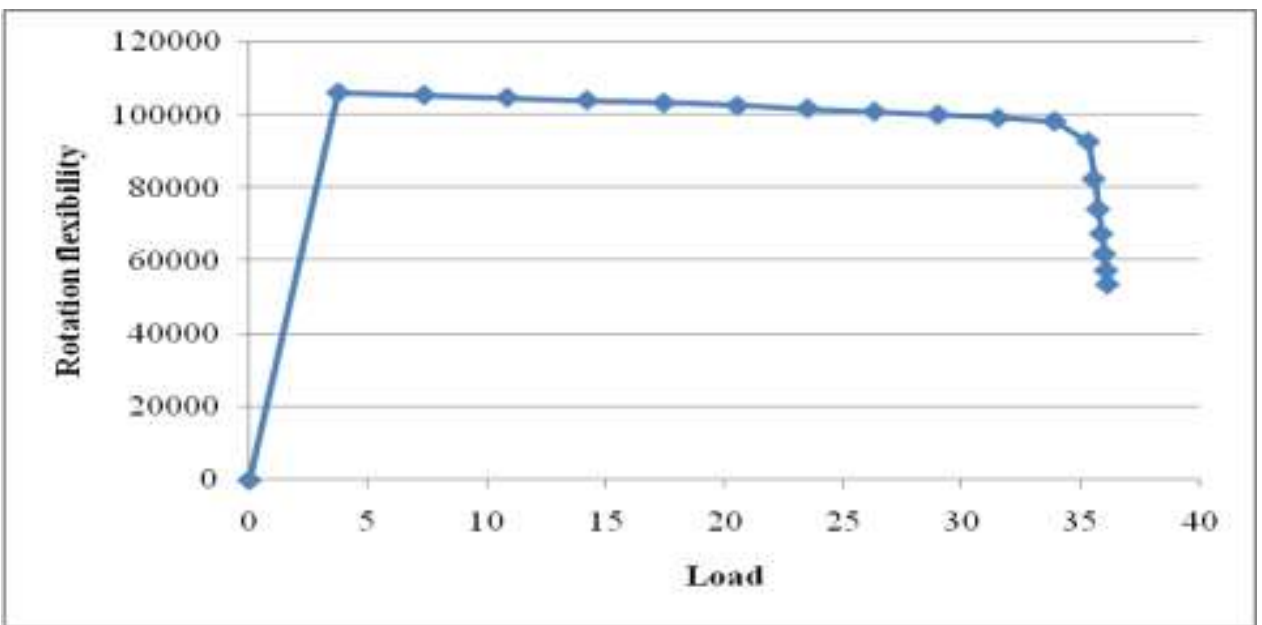

Fig 25 Rotation Flexibility vs Load (for uniformly distributed load along the span)

\section{CONCLUSION}

The following conclusions are made in this paper work

- Higher the grade of concrete, lower the failure strain.

- Increasing the compressive strength of concrete increases the moment resistance but not its ductility behavior.

- Under-reinforced section gains more rotation on increasing the amount of reinforcement in tension side.

- A decrease in rotation flexibility indicates that lesser moment is required for rotation as it approaches collapse.

- There is a $30 \%$ increase in moment carrying capacity when the singly reinforced section is used as doubly reinforced section with $\mathrm{Asc}=$ Ast.

- Rotation flexibility (moment required to produce unit rotation) decreases as the strain increases.

- Rotation ductility and energy decreases as compressive strength of concrete increases.

- Rotation ductility increases as the amount of reinforcement in tension side increases (which is underreinforced in both actual and design case).

- Energy increases as the amount of tension reinforcement increases from minimum to Ast.

- Rotation ductility and energy decreases as the compression reinforcement increases from minimum till Asc $=$ Ast .

- Moment rotation behaviour of RC beam cross section is studied.

- Decrease in stiffness and rotation flexibility is observed on the increase of load on the RC beam.

\section{REFERENCES}

[1] Marjanishvili, S. M. "Progressive analysis procedure for progressive collapse." Journal of Performance of Constructed Facilities 18.2 (2004): 79-85

[2] [Buscemi, Nanci, and Shalva Marjanishvili. "SDOF model for progressive collapse analysis." Metropolis and Beyond. 2005.

[3] Inel, Mehmet, and Hayri Baytan Ozmen. "Effects of plastic hinge properties in nonlinear analysis of reinforced concrete buildings." Engineering structures28.11 (2006): 1494-1502.

[4] Kheyroddin, Ali, and Hosein Naderpour. "Plastic hinge rotation capacity of reinforced concrete beams." Int. J. Civ. Eng 5.1 (2007): $30-47$.

[5] Srikanth, M., G. Rajesh Kumar, and S. Giri. "Moment Curvature Of Reinforced Concrete Beams Using Various Confinement Models And Experimental Validation." Asian Journal Of Civil Engineering (Building And Housing) 8.3 (2007): 247-265.

[6] Kulkarni, Abhay A., and Rajendra R. Joshi. "Progressive Collapse Assessment of Structure." International Journal of Earth Sciences and Engineering, 04 (2011): 652-655.

[7] Pachenari, Alireza, Abolghassem Keramati, and Zahra Pachenari. "Investigation of progressive collapse in intermediate RC frame structures." The Structural Design of Tall and Special Buildings (2010).

[8] Harinadha Babu Raparla, Narender Bodige and Ramancharla Pradeep Kumar. "2D Numerical Modelling of Progressive Collapse during Earthquakes: A Case Study on RC Bare Frame.” Proceedings of International Conference on Advances in Civil Engineering, ACE, (2011): 1-25.

[9] Kadid, A., and A. Boumrkik. "Pushover analysis of reinforced concrete frame structures." Asian Journal of Civil Engineering (building and housing) 9.1 (2008): 75-83.

[10] Masoero, E., et al. "Progressive collapse mechanisms of brittle and ductile framed structures." Journal of engineering mechanics 136.8 (2010): 987-995.

[11] "Plain and reinforced concrete-code of practice." IS456-2000 Bureau of Indian Standard, New Delhi, India. 